\title{
CFD Analysis to Calculate the Optimal Air Velocity in Drying Green Tea Process Using Fluidized Bed Dryer
}

\author{
Eflita Yohana ${ }^{1, *}$, Afif Prasetya Nugraha ${ }^{2}$, Ade Eva Diana ${ }^{2}$, Ilham Mahawan $^{2}$, and Sri Nugroho ${ }^{1}$ \\ ${ }^{1}$ Department of Mechanical Engineering, Faculty of Engineering, Diponegoro University, Semarang - Indonesia \\ ${ }^{2}$ Undergraduate of Mechanical Engineering Department, Faculty of Engineering, Diponegoro University, Semarang - Indonesia
}

\begin{abstract}
Tea processing is basically distinguished into three types which black tea, green tea, and oolong tea. Green tea is processed by heating and drying the leaves. Green tea factories in Indonesia are generally using the process of drying by panning the leaves. It is more recommended to use the fluidization process to speed up the drying process as the quality of the tea can be maintained. Bubbling fluidization is expected to occur in this research. It is a process of bubbles are formed in the fluidization. The effectiveness of the drying process in a fluidized bed dryer machine needs to be improved by using a CFD simulation method to proof that $u_{m f}<u<u_{t}$, where the average velocity value is limited by the minimum and the maximum velocity of the calculation the experimental data. The minimum and the maximum velocity value of the fluidization is $0.96 \mathrm{~m} / \mathrm{s}$ and $8.2 \mathrm{~m} / \mathrm{s}$. The result of the simulation obtained that the average velocity of the upper bed part is $1.81 \mathrm{~m} / \mathrm{s}$. From the results obtained, it can be concluded that the calculation and the simulation data is in accordance with the condition of bubbling fluidization in fluidized bed dryer.
\end{abstract}

\section{Introduction}

Tea is a beverage form widely consumed in many countries. This beverage contains numerous active ingredients that act as both anti-oxidants and antimicrobials. Essentially, tea is processed into three various kinds which are black tea, green tea, and oolong tea. The amount of tea in the world that is processed into black tea is more than three quarters part of it. The process of black tea processing includes leaves chopping, and then drying the chopped ones in the sun until there is a chemical change that turns the leaves colour to brown and also provides a distinctive taste in the tea. For green tea, its leaves are heated only the directly dried so that the leaves colour remain the same. Oolong tea itself is a transitional type between black tea green tea. There is a fermentation occur in its processing that creates different flavour and characteristics to oolong tea. Also, the tea has health benefits and potentials that is as same as other tea _[1].

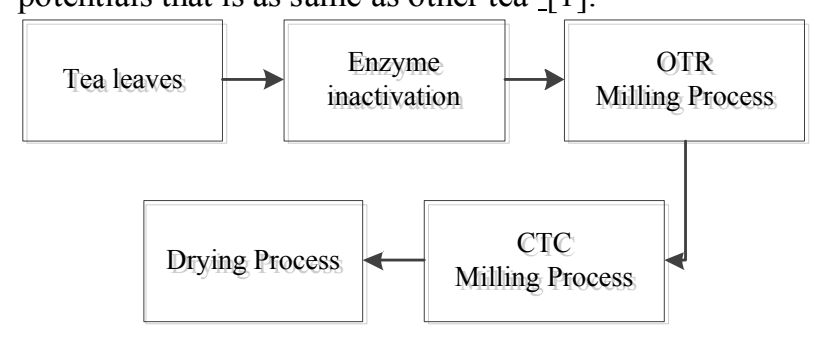

Fig. 1. Green tea processing [2].
A number of studies have found that catechins are such compound that is most responsible for the healthful effects that tea could provide. For instance, green tea is not only used as beverage products, but it also has an important component that can be used for foods, pharmaceutical, body and beauty products. The process scheme in Figure 1 shows the latest technology of green tea processing that works in to obtain a higher cathecin content than the one that is generated from conventional processing. In order to produce such green tea is by inactivating the enzyme polyphenol oxidize enzyme through steaming process that is applied evenly throughout the leaves' surface. Then proceed with a milling process which is a combination of OTR (Open Top Roller) and CTC (Crushing Tearing Curling) to increase the dissolved soils. The last process is namely drying process. This process uses fluidized bed dryer to get the tea leaves that contain water content of $4 \%-5 \%$ and to avoid over burnt tea leaves in the drying process [2].

The fluidization drying method is used to speed up the drying process and maintain the leaves quality. This drying method is widely applied to dry such particulate or granular materials used for chemical, food, ceramic, pharmaceutical, agricultural, polymer and waste industries. There is a materials blowing occurring in this condition, thus it expands the drying area, increases the convection heat transfer coefficient and the rate of vapor diffusion. In order to achieve a fluidization condition, the

Corresponding author: $\underline{\text { efnan2003@gmail.com }}$ 
airflow velocity must be greater than the minimum fluidized velocity in which the dried materials can still be fluidized properly. When the airflow velocity is increased during this process, the static pressure of the drying air increases and the dried material is lifted to a certain height (floating) and causes the material be fluidized. In this condition, the material is uniformly stirred and the air cushion that holds the material at a certain height is in a minimum fluidized state [3].

The minimum fluidization velocity $U_{m f}$ is used to determine the fluidization starting point so that the compressed lost value at the beginning state of the fluidization can be calculated. The minimum velocity fluidization equation is generally written as following equation :

$$
U_{m f}=\frac{\left(\psi d_{p}\right)^{2}}{150 \mu}[g(\rho c-\rho g)] \frac{\varepsilon_{m f}^{3}}{1-\varepsilon_{m f}}
$$

where $\psi$ is sphericity, $d_{p}$ is particle diameter, $g$ is gravity, $\rho_{c}$ is the mass of the particle type, $\rho_{g}$ is the vapor type mass, $\varepsilon_{m f}$ is the porosity at the minimum state of fluidization [4]. There are several phenomenons that occur in the fluidization process, which they are [3] :

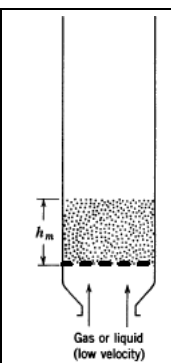

(a)

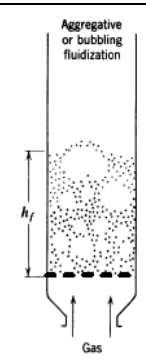

(b)

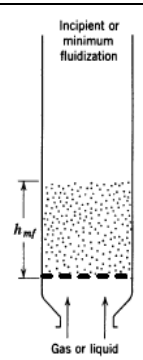

(c)

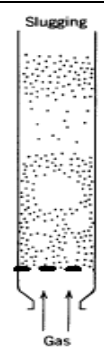

(d)
Fig. 2. Occurring phenomenon in fluidization process (a) fixed bed $u<u_{\mathrm{mf}}$ (b) Minimum Fluidization $u=u_{\mathrm{mf}}$ (c) Bubbling Fluidization $u>u_{\mathrm{mf}}, u<u_{\mathrm{t}}$ (d) Slugging [3].

a. The fixed bed phenomenon will occur when path for the fluid flow is less than the minimum rate that is required for the initial fluidization process. In this particular condition, the solid particles will remain stationary. The aforementioned phenomenon is shown in Figure 2(a).

b. The minimum phenomenon or incipient fluidization occurs when the fluid flow rate reaches the minimum flow rate that is required for the fluidization process. The solid particles begin to expand or float in this condition. This phenomenon is shown in Figure 2(b).

c. The bubbling fluidization phenomenon will occur when the density and distribution of the particles are not homogeneous, thus resulting in bubbles in the fluidization process. This phenomenon can be seen in Figure 2(c).

d. The slugging phenomenon will occur when the large bubbles that reach the column diameter width are formed in the solid particles. In this condition, there is a rampage so that the solid particles are lifted up.

The just aforementioned phenomenon can be seen in Figure 2(d).

In the present study, fluidization can be used to speed up the drying process as well as to maintain the quality of the tea. Bubbling fluidization is expected to occur. It is a process of bubbles are formed in the fluidization. The effectiveness of the drying process in a fluidized bed dryer machine can be improved by using a CFD simulation method.

\section{Research methods}

\subsection{Flow chart of research}

The flow chart used for this study is shown in Figure 3 below.

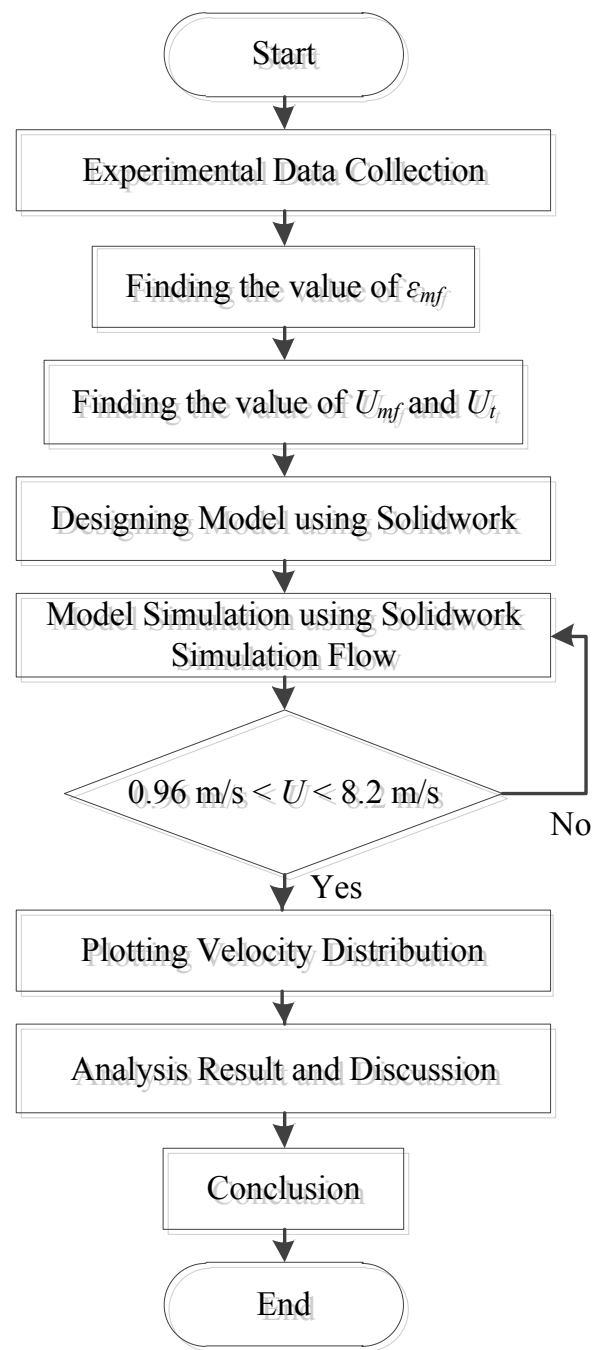

Fig. 3. Flow chart of research. 


\subsection{Experimental data}

The data was collected at a tea factory located in Cibuni Estate area, West Java on a fluidized bed dryer with the following parameters in Table 1.

Table 1. Parameters and operating conditions in numerical simulations.

\begin{tabular}{|c|c|}
\hline Parameter & Values \\
\hline Temperature inlet & $130^{\circ} \mathrm{C}$ \\
\hline Velocity inlet & $2.6 \mathrm{~m} / \mathrm{s}$ \\
\hline Particles diameter & $0.5 \mathrm{~mm}$ \\
\hline Particles weight & $0.0016 \mathrm{gr}$ \\
\hline Pressure & $2.5506 \mathrm{bar}$ \\
\hline
\end{tabular}

\subsection{Data calculation as parameter form}

This calculation was done to look for the minimum porosity value of fluidization $\left(\varepsilon_{m f}\right)$. It is used to find the minimum fluidized velocity value, as well as the maximum velocity value of fluidization.

$$
\varepsilon_{m f}=0.586 \psi^{-0.72}\left(\frac{\rho_{g}}{\rho_{c}}\right)^{0.021}\left(\frac{\mu^{2}}{\rho_{g} \eta d_{p}^{3}}\right)^{0.029}
$$

where $\varepsilon_{m f}$ is the porosity at the minimum of fluidization, $\psi$ is sphericity, $\mu$ is viscosity, $\eta$ is gravitation term, $d_{p}$ is particle diameter, $\rho_{g}$ is density of the fluid, $\rho_{c}$ is density of the particle [5]. The value are $\psi$ $=0.33, \rho_{g}=0.00078, \eta=239700.38, \mu=0.282$, $\rho_{c}=24.46$ and $\varepsilon_{m f}$ is 0.888 .

\subsection{Velocity analyze simulation}

The problem to be discussed in this study is the velocity analysis on fluidized bed dryer. The models are made using Solidworks. The assumptions used in the simulation are seen in few following points, which are :

1. Fluid velocity inlet of $2.6 \mathrm{~m} / \mathrm{s}$

2. The fluid used is in steam

3. Simulation is in steady state condition

4. The absence of heat transfer

5. The flow appears as turbulent flow

6. The pressure used is environmental stress of $101325 \mathrm{~Pa}$

\subsection{Fluidized bed geometry}

The geometry on fluidized bed design is modeled by Solidworks software. This model is shown in Figure 4 below, which consists of some models that are assembled together into one single unit.

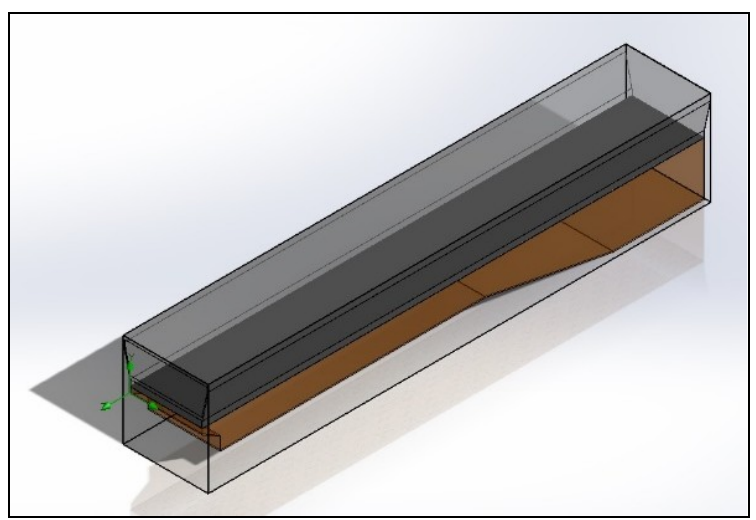

Fig. 4. The overall looks of assembly model.

\section{Analysis results}

\subsection{Calculation of minimum fluidization velocity}

The calculation of minimum fluidization velocity resulted as follows :

$$
u_{m f}=\frac{\left(\psi d_{p}\right)^{2}}{150 \mu}[\mathcal{g}(\rho c-\rho g)] \frac{\varepsilon_{m f}^{3}}{1-\varepsilon_{m f}}
$$

where $\eta=g(\rho c-\rho g)$ [4]. The value are $d_{p}=0.5$ and $u_{m f}=0.96 \mathrm{~m} / \mathrm{s}$.

\subsection{Calculation of maximum fluidization velocity}

The calculation of maximum fluidization velocity resulted as follows [3]:

$$
U_{\mathrm{t}}=\left(\frac{1.78 \times 10^{-2} \eta^{2}}{\rho_{\mathrm{g}} \mu}\right)^{\frac{1}{3}} \mathrm{~d}_{\mathrm{p}}
$$

where the value are $u_{\mathrm{t}}=8.2 \mathrm{~m} / \mathrm{s}$.

\subsection{Simulation result analysis}

The simulation result on fluidized bed can be seen in Figure 5.

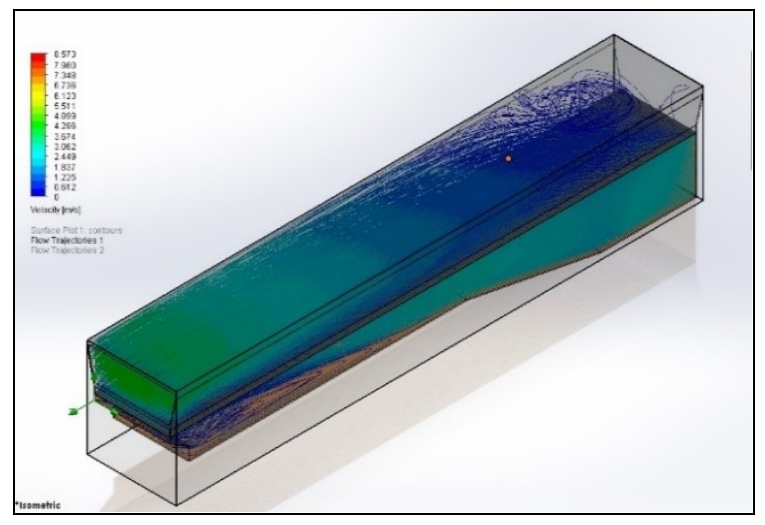

Fig. 5. The overall look of simulation result. 


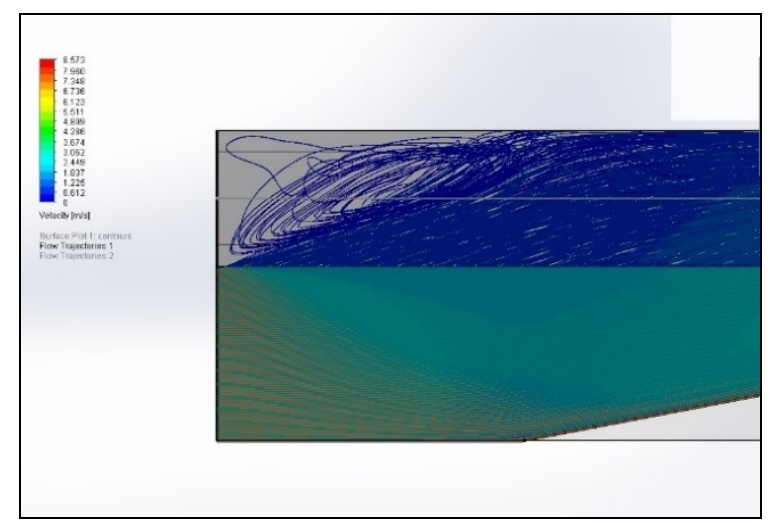

Fig. 6. The above view is zoomed particularly in the inlet area.

Figure 6 shows that when fluid enters the column side, the velocity increases as the lower bed crosssectional area diminishes. We can also see in it that the fluid passing through the velocity filter will later decrease.

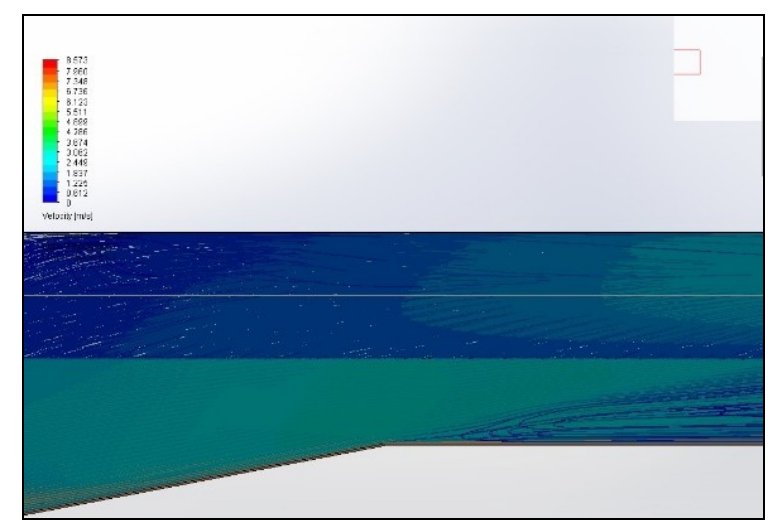

Fig. 7. The view is zoomed-in in the middle area of fluidizied bed.

Figure 7 shows that the lower bed velocity is increased due to the smaller cross-sectional area caused by the shape of the lower bed base leading to this that causes the fluid passing through the velocity filter is also increasing. We can also see in the upper bed that the fluid velocity increases too that is caused by the shape of the lower bed base that shrinks and points upward.

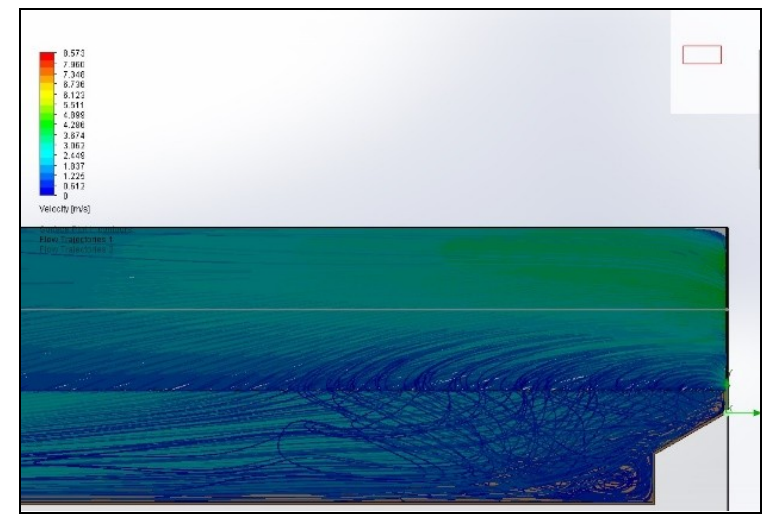

Fig. 8. The view is enlarged around outlet area.

Figure 8 shows that the fluid trapped in the lowerbed end makes a turbulence that serves to lift the falling particles from the filter so that the particles will rise back upward. On the upper bed, it indicates that the velocity of the outlet starts to accelerate according to the law of continuity; this is due to the fluid insistence from the lower bed that is getting more toned once it gets toward the end.

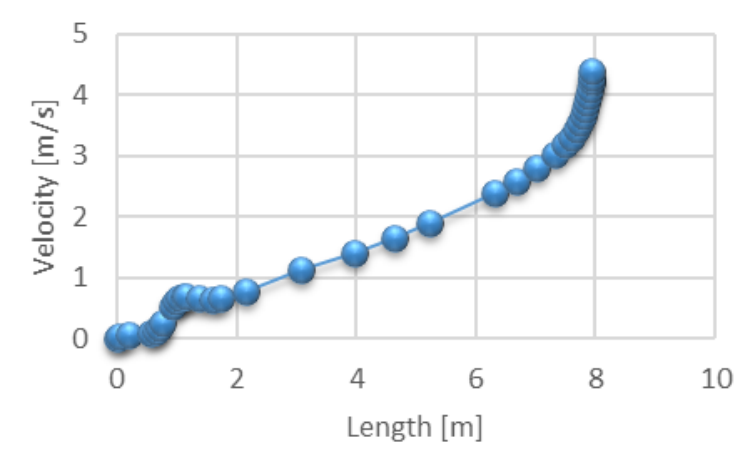

Fig. 9. Graphs of plot result in upperbed area.

Figure 9 above is a graph of the plot result in upper bed area. We can know from the graph that the fluid velocity is increasingly close to the oulet end of the bed. The average speed that occurs along the upper bed area is $1.81 \mathrm{~m} / \mathrm{s}$.

\section{Conclusion}

Prior calculating all of the data manually and conducting the simulation with Solidworks, the minimum fluidization velocity $\left(u_{m f}\right)$ was $0.96 \mathrm{~m} / \mathrm{s}$, the average fluidization velocity value $(u)$ was $1.81 \mathrm{~m} / \mathrm{s}$, and the maximum fluidized velocity value $\left(u_{\mathrm{t}}\right)$ was $8.2 \mathrm{~m} / \mathrm{s}$. Overall, it can be concluded that from the results obtained, it can be expressed by following condition $u_{m f}<u<u_{\mathrm{t}}$; that the minimum fluidization velocity of $0.96 \mathrm{~m} / \mathrm{s}$ is less than the average fluidization velocity of $1.81 \mathrm{~m} / \mathrm{s}$, and the average fluidization velocity is less than the maximum fluidization velocity of $8.2 \mathrm{~m} / \mathrm{s}$. This expression indicates that the calculation and simulation data is already in accordance with the condition of fluidization rule with such bubbling fluidization phenomenon occurs on fluidized bbed dryer. Whereas the bubbling fluidization phenomenon turns to be the best phenomenon to achieve a fluidization condition on the fluidized bed dryer machine.

\section{References}

1. A.D. Ananda, Aktivitas Antioksidan dan Karakteristik Organolaptik Minuman Fungsional Teh Hijau (Camellia Sinensis) Rempah Instan, Bogor: Fak Pertanian Institut Pertanian Bogor, (2009).

2. J. Towaha, Kandungan Senyawa Kimia Pada Daun Teh (Camellia Sinensis), Warta Penelitian dan Pengembangan Industri, 19 no 3, (2013). 
3. M. Sadeghi, Vibration Effect on Particle Bed Aerodynamic Behavior and Thermal Performance of Black Tea in Fluidized Bed Dryers. Iran: Tarbiat Modares University, (2012).
4. W. Widayati, Fenomena dan Kecepatan Fluidisasi $\left(U_{m f}\right)$, 10, (2010).

5. Pabis, Measurements of porosity of gas - solid fluidized bed, (2002). 